Binomials and the noun-to-verb ratio in Puma Rai ritual speech

Gaenszle, Martin ; Bickel, Balthasar ; et al

Posted at the Zurich Open Repository and Archive, University of Zurich ZORA URL: https://doi.org/10.5167/uzh-71151

Journal Article

Originally published at:

Gaenszle, Martin; Bickel, Balthasar; et al (2011). Binomials and the noun-to-verb ratio in Puma Rai ritual speech. Anthropological Linguistics, 53:365-381. 


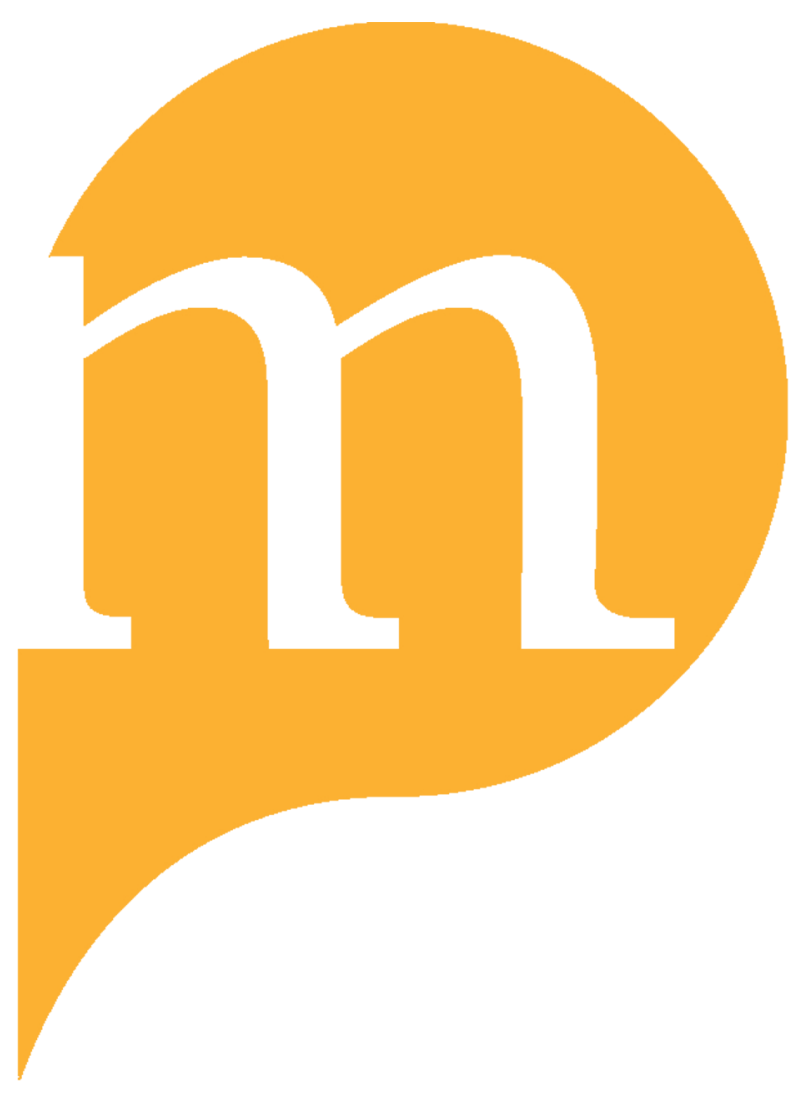

PROJECT MUSE 


\title{
Binomials and the Noun-to-Verb Ratio in Puma Rai Ritual Speech
}

\author{
MARTIN GAENSZLE (University of Vienna), BALTHASAR BICKEL \\ (University of Zurich), NARAYAN P. SHARMA (University of \\ London), JUDITH PETTIGREW (University of Limerick), ARJUN \\ RAI (Tribhuvan University, Kathmandu), SHREE KUMAR RAI \\ (Tribhuvan University, Kathmandu), and DiAnA ScHACKOW \\ (University of Leipzig)
}

\begin{abstract}
This article examines the pairing of nouns in the type of parallelism known as binominals, expressions of paired words, in Puma Rai ritual speech. Using a large corpus of ritual and everyday language texts resulting from a language documentation project among the Puma Rai in Nepal, we explore the characteristics of ritual binomials and provide a quantitative analysis of noun-to-verb ratios in the two major ritual speech genres (shamanic and priestly invocations). It is argued that the increase of nouns in the ritual language under study leads to an inversion of the noun-to-verb ratio in relation to ordinary speech.
\end{abstract}

1. Introduction. A widespread feature of ritual languages around the world is the pervasive use of parallelisms (Fox 1977, 1988). As studies have shown, numerous kinds of parallelism are found at different levels of grammar, such as syntactic, prosodic, and semantic. From this wide range of parallel forms, this article focuses on the level of the word, and more specifically, the noun, and examines the particular phenomenon termed binomials, ${ }^{1}$ i.e., expressions that consist of two linked forms, in the Puma Rai language of Nepal. ${ }^{2}$ Other terms one finds in the literature on binomials are "twin words," "word pairs," "paired terms," "polar expressions," "Synonymenbinom," and, in the case of nouns, "paired nouns," "linked nouns," or "compound nouns" (see below). While this can be seen as a minimal case of parallel structure, it should be stressed that not all ritual languages marked by parallelism contain such binomials. As a result, the question we raise here is: why do binomials occur? Or, more specifically, we ask in a praxis-oriented anthropological perspective: why are binomials used and what is their effect in ritual performance?

In this article we first review the various approaches to the study of binomials in light of a comparative perspective on ritual speech. In particular, we look at the various attempts to explain the occurrence of binomials and their role in ritual languages or registers. Most of these approaches have made solid contributions to our understanding of the phenomenon. However, until now, one point has been neglected: the doubling of nouns generally leads to a significant increase in the noun-to-verb ratio, as verbal forms (and other parts of speech) tend to be less affected by the twinning process. We present a case study of Puma Rai ritual language, a register of speech still practiced by a small ethnic 
group in eastern Nepal, although it is highly endangered. ${ }^{3}$ The language belongs to the Kiranti group of the Tibeto-Burman family, which has been the subject of the interdisciplinary Chintang and Puma Documentation Project. We argue that the relatively high noun-to-verb ratio in ritual speech is a direct inversion of the situation of ordinary speech, where the noun-to-verb ratio is relatively low. ${ }^{4}$ This suggests that the effect of binomials in ritual speech cannot be judged by studying ritual genres alone, but has to be seen in the context of the total field of speech practices.

2. The study of binomials in linguistic anthropology. Ever since Roman Jakobson's pathbreaking work on parallelism (Jakobson 1966), binomials have been studied as a particular case of this larger phenomenon.

Jakobson defines "canonic parallelism" in terms of "poetic patterns where certain similarities between successive verbal sequences are compulsory or enjoy a high preference." He continues:

Such traditional types of canonic parallelism offer us an insight into the various forms of relationship among the different aspects of language and answer the pertinent question: what kindred grammatical or phonological categories may function as equivalent within the given pattern? [1966:399]

For Jakobson this kind of functional equivalence was at the base of all poetic language (Jakobson 1960). Taking up ideas from the early biblical studies on "parallelismus membrorum” in Hebrew begun by Bishop Robert Lowth in 1753, Jakobson focuses mainly on parallel lines. Though these may contain "parallel terms" (as was already observed by Lowth), Jakobson does not single out binomials as a phenomenon in their own right. He does, in fact, use the term at one point in the analysis of Hebrew verses (1966:426), but it appears descriptively in the sense of "two words per line" (along with "trinomial”), not as a technical term in its own right.

It should be stressed at this point that parallelism as analyzed by Jakobson should not be restricted to pairing, i.e., linking of only two verbal sequences. Though, in fact, this is what is usually found in the academic discussion of parallelism (including that by Jakobson), there can also be more than two parallel sequences. The strength of Jakobson's formal approach is that it can account for more than two parallel elements-functional equivalence can occur in a whole series of parallel verbal sequences.

For Jakobson, the reason for such parallel structures is basically aesthetic; it is a playful expression of linguistic structures, summed up in his famous phrasing that "the poetic function projects the principle of equivalence from the axis of selection into the axis of combination" (1960:358). This process is closely linked to oral genres (e.g., Russian folk songs), where repetition and rhythm play an important role. Binomials are simply a variant of parallelism and are not treated as a special case. 
The first in-depth linguistic study of binomials as such is an article by Yakov Malkiel (1959). He defines a binomial as "the sequence of two words pertaining to the same form-class, placed on an identical level of the syntactic hierarchy, and ordinarily connected by some kind of lexical link" (1959:113). Malkiel attempts to establish the broader meaning of the concept, which, in some usages, only includes cases of alliteration (e.g., bear the badge). His definition of binomials includes not only nouns (e.g., cold and snow), but also other word classes, such as adjectives (e.g., black and white), or verbs (e.g., shoot and kill). Within this larger category, his article focuses on one particular subset of binomials characterized by irreversibility (e.g., fish and chips and not chips and fish). The question Malkiel then raises concerns the regularity of sequencing: what are the reasons for a particular combination? Malkiel isolates six forces that are effective in various combinations. While some are purely formal (e.g., following prevalent prosodic patterns), others are linked to social and cultural values, such as father and mother, which implies a hierarchy. Thus, poetic features are closely interlinked with a "social prism" that reflects a particular society.

This social dimension has also been stressed by the anthropologist James Fox, who has taken up these structuralist ideas, in particular those developed by Jakobson. In his work on Rotinese ritual language (Indonesia), he points out the pervasive "canonical" pairing of words in parallel phrases ${ }^{5}$ and suggests that they indicate a "cultural code" (Fox 1975:111). Moreover, he speculates that the dualism might be related to the prevalence of a dualistic perception of the world as manifested in forms of dual classification (Fox 1988:26). However, as the elements in Rotinese pairings are often paired in various different constellations, thus forming a "network of interlinkages" (Fox 1977:79), he remains skeptical about a direct correlation between linguistic and social dualism, stressing that only "a relatively limited set of pairs is utilized in systems of dual classification" (Fox 1988:27). However, comparative research is still in its early stages, and it is striking that in the Tibeto-Burman-speaking groups of the eastern Himalayas, both canonical parallelism in ritual speech and dual symbolic classification are relatively widespread. ${ }^{6}$

A similar kind of word pairing is described by Joel Kuipers in Weyewa ritual speech on Sumba, another island of Indonesia. The parallel lines or couplets, locally termed "speech that is paired," are seen as the essential characteristic of ancestral speech and mark the texts as "authoritative” (Kuipers 1990:71-79). However, Kuipers points out that the pairings of the semantic "kernel" elements, the word pairs, do not reflect any systematic cultural contrasts, but often are formed on purely phonetic or prosodic grounds (Kuipers 1990:76-77). In any case, what is interesting for our present study is the occurrence of "couplet names," i.e., proper names of individual persons and places that consist of two (often multinomial) parts. Such names are imbued with particular power; they are "reverential titles, whose use not only indexes respect of the speaker toward 
the referent, but also indexes the authority of the referent itself" (Kuipers 1990:77). In other words, it is an expression of ancestral sacredness.

This brings us to the use of binomials as described among Tibeto-Burmanspeaking tribal groups in the central and eastern Himalayas. In his pathbreaking article on Rai ritual speech, Nicholas J. Allen (1978) for the first time describes "binary ritual language expressions" among the Thulung Rai. Allen describes the ritual language as a language "diatype" (i.e., linguistic register) which is "appropriate for addressing ancestors and spirits," (1978:239) and in principle, everything mentioned in the ritual must have a ritual name (1978: 242). The Thulung Rai term (and similar expressions are found in other Rai languages) is depcinəך (dep- 'to invoke', nәך 'name'), i.e., 'invocation name' (1978:241). ${ }^{7}$ This kind of name is particularly used for sacred objects, such as the sacred hearthstones or offerings, but also for certain kinds of categories and activities. Allen further analyzes the binary language expressions morphologically as paired disyllabic or trisyllabic "limbs" with more or less distinct meanings. ${ }^{8}$ He sees the phenomenon as somehow "intermediate" between the canonical parallelism described by Fox and Jakobson and the irreversible binomials described by Malkiel (Allen 1978:251).

Gaenszle's study of Mewahang Rai texts (Gaenszle 2002) expands research on binomials in Rai ritual speech. Differing from Allen's account, Gaenszle finds three types of nouns in Mewahang ritual speech: ordinary language expressions, ritual terms consisting of one word, and binomials (as well as trinomials and sometimes multinomials). The latter are regarded as particularly powerful; they have a special "force" through which the ritual expert can exert control over the world (Gaenszle 2002:161). Similar observations have been made in the case of Chintang (Gaenszle et al. 2005; Rai 2007; Rai et al. 2009). Employing and further elaborating the representational system proposed by Allen, these studies explore the morphological structure of binomials. Though many of the elements defy semantic analysis, it is nevertheless evident that the ritual terms are intrinsically meaningful and not simply "mumbo jumbo" (thus confirming Allen's earlier observation). Often they contain Tibeto-Burman roots (e.g., *luy, *bun, *kha, or *wa), but they may also incorporate new lexical material (e.g., from the Nepali language). In addition, Vorberg et al. (2009) have shown that the phonological structure of binomials is constrained by a small set of principles on the order of the limbs (e.g., principles favoring the sounds $s$ and $a$ in the first limb, syllable-final nasals and $u$ in the second). This latter argument suggests that binomials reflect a fully structured subpart of grammar.

Although the existence of binomials is particularly widespread in Kiranti ritual speech, it should be emphasized that they also occur in other TibetoBurman ethnic traditions. In his study of Tamu (Gurung) ritual texts, Strickland (1987) reports the use of irreversible binomials, nouns as well as some verbal expressions. The term for the Tamu oral ritual tradition itself is a typical binomial: pe-da lu-da (example-word principle-word). Strickland classifies them 
as "expressive reduplicatives," since the final morpheme of the first limb is repeated with a different initial morpheme. It is well known that in South Asia reduplication, especially in ideophones, is a common feature in ordinary speech. The same is true among the Tamu (and throughout the Kiranti area for that matter). But what is unique in ritual speech is that the repetitive pairings often combine contrasting elements that add up to the general meaning. However, this is not always the case, as Strickland concludes: "Most of these instances consist of two limbs or entities and the global sense may or may not equal the sum of the elements" (1987:63).

Similar observations can be made about ritual speech among the Tamang in Nepal (whose language, like Tamu, is classified as Bodish). Höfer analyses binomials (along with echo words) as one class of "binarism," which he defines as "any coupling of two units (terms, phrases) into a pair justified by any structuring principle whatsoever" (1994:295). Höfer's second class is "paratactic configurations, which in some instances are identical with parallelism" (1994: 295); these are basically what are described above as "parallel phrases," "parallel lines," or "couplets." Interestingly, Höfer regards these kinds of binarism as a special case of the more general feature of "enumerations" (1994:284-300)—in other words, as indicated above, the parallel configurations are not necessarily restricted to a binary principle. Rather, one can distinguish a continuum with "asyndetonic enumerations" at one end, binarism at the other, and triadic and tetradic patterns in between (1994:295). Still, the binary principle is semantically distinctive, drawing either on an oppositional or complementary relationship.

That the phenomenon is not restricted to the Nepal Himalayas, but is equally pervasive in the ritual languages of Tibeto-Burman-speaking ethnic groups in northeastern India is shown in a recent monograph on the Apa Tani (Blackburn 2010). Blackburn points out that (unlike the Kiranti case) not more than two nouns are conjoined in what he calls "noun-pairs" in ritual speech. Another interesting feature is that often both nouns in a pair have exactly the same meaning or referent, one noun being a ritual term and the other the ordinary language term (2010:155). But in many noun-pairs the relationship is ambiguous or difficult to explain. In any case, Blackburn describes the use of these expressions mainly as a use of poetic strategies-they facilitate the production of various parallelistic syntactic patterns or structures.

To conclude, most approaches have tried to explain the existence of binomials in one or several of the following ways:

- The poetic approach explains binomials in terms of formal linguistic properties. Parallelism makes use of structural features (symmetry, repetition, enumeration, etc.) and is appealing to the senses; it is aesthetically gratifying, harmonious, or playfully expressive.

- The sociological approach explains them in terms of the ritual significance of binomials-in particular, ritual names, which imply sacredness and a 
special power, generally derived from the authority of an "archaic" ancestral tradition.

- The culturalist approach explains them in terms of the binomial's semantic structure (opposition, complementarity, etc.), which implies a "cultural code."

While all these approaches have their justification and have contributed to our understanding of ritual speech, there is one point that has so far received little attention-the effect of binomials as an inversion of everyday language. This effect is manifested first and foremost by the ratio of nouns and verbs in discourse. We take a closer look at this in the study of Puma below.

3. Ritual nouns in Puma ritual speech. The traditional settlement area of the Puma Rai is the valley of the Ruwa Khola River (in Khotang District), a tributary of the Buwa Khola River, which flows into the Sun Koshi River in eastern Nepal. The Puma number about six thousand, residing in five village districts (Village Development Committees), with settlements spread on both sides of the Ruwa Khola. There are also Puma who have moved southward across the Sun Koshi and settled in Udaipur District. The Puma language is still widely spoken in all the village districts in the Ruwa Khola. Most Puma there speak three languages: Puma, Bantawa, and Nepali. In mixed settlements where other Rai groups are also found (as in Udaipur District, but also in the Puma homeland area), Bantawa is generally used as a lingua franca. Some speakers even speak four or more languages (mainly other Rai languages and Hindi, as well as English). In any case, due to the increasing influence of Nepali, the national language, the Puma language is in decline.

The term mundhum (variants of which are found among most Rai groups; see Gaenszle 2002:39-44) refers to the Puma oral tradition, which includes recitations spoken or chanted in a distinctive ritual language. These include, for example, ritual invocations of the ancestors during funerals or harvest festivals, ceremonial dialogues on occasions such as weddings, or complex shamanic séances for the purpose of healing. Oral texts and ritual are interlinked. They commemorate the mythical deeds of the ancestors and, through the performances, the living communicate with the ancestral beings to ensure their continued blessing and protection in the present.

The main ritual expert among the Puma is the yapon, which can be rendered as 'priest' (in Nepali it was translated as kul pujāri, the standard term for a family priest in Hindu traditions). A yapon can be either male or female, although most napons are male. Competent in the mundhum ritual language,

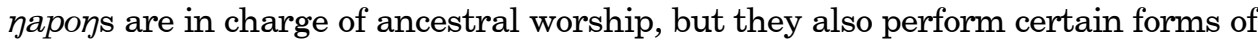
healing and divination rituals. To become a napon, a person has to receive a calling in his or her dreams. They are taught through dreams by Paruhang, the god of creation, over a period of about a year. During this time they receive knowledge of the mundhum ritual language and also learn the techniques of 
how to perform the ancestor's rituals. Novice napons also learn about ritual performance by observing and questioning experienced napons and practicing when performing rituals. Junior napons work alongside, and learn from, more senior napons.

The Puma also have shamans called rahaymi supsanmi (itself a binomial). They are likewise ritual experts, but have more detailed ritual and cultural knowledge than yapons. All shamans can perform the same rituals conducted by napons. However, only shamans can chant during the funeral procession and only they can perform the night-long healing séances, in particular the Budhahay and Guru pujā rituals. ${ }^{9}$ These rituals require the knowledge of lengthy texts, which include, for example, invocations of various divine beings, enumerations of offerings, and long recitations of place names through which the shaman undertakes ritual journeys. Thus, the speech genres of each of these of ritual experts are distinguished by different degrees of linguistic competence. Shamans must experience a particular kind of dream as part of their initiation; otherwise, they put their lives at risk. If a shaman performs the Budhahan ritual without having seen Budhahay in a dream, then, it is said, this will have a negative impact and cause misfortune, illness, and possibly death.

One of the most distinctive features of Puma ritual language is the use of binomials in the chanting styles of yapons and shamans. In Puma mundhums, as in other Rai mundhums, there are also many everyday language terms, as well as ritual language elements that are not binomials. Consider the yapoy invocations in (1) and (2).

(1) soi carikuruך khopdaluฑbo kısaya rımrepdei

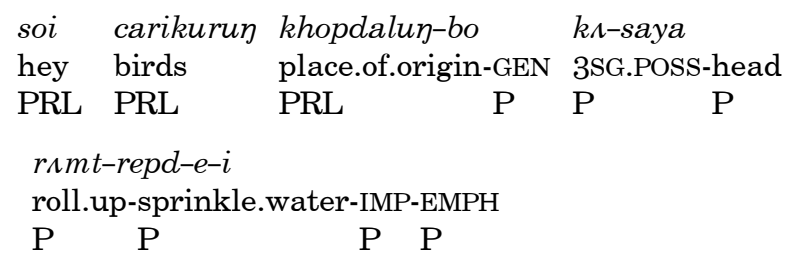

'Bless the soul of the birds and their place of origin!' (ngapong_01.001) ${ }^{10}$

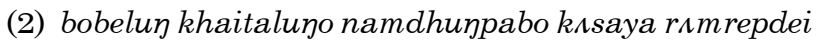

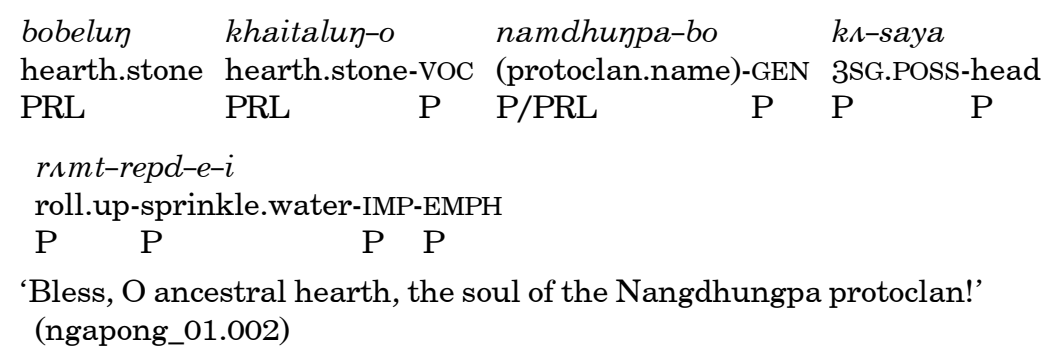

In both (1) and (2), the term saya is used in a possessive construction that would have exactly the same structure in colloquial speech. Similarly, the verbal 
phrase rumrepdei, repeated at the end of each sentence, is also no different from that found in the ordinary language. The term carikuruy 'birds' in (1), however, would be wasa in ordinary speech. The ritual expression evokes not only birds as an abstract class, but the entire variety of different bird species that were created at the mythical place of origin, referred to here as khopdalun. Both of the terms carikuruy and khopdaluy are ritual nouns that can stand alone, but here they are combined in a regular coordinate structure meaning 'birds and their place of origin'. This construction is not a standardized binomial, since the referents of its two components are still understood to be distinct, but it can be thought of as a binomial in a wider sense of the term. The situation is different in the case of the term bobeluy khaitalun in (2). This expression is a typical ritual binomial in the narrower sense: it is a standard or "canonical" term that only occurs in the given, irreversible form and has one global referent (here the hearth). This variety of different types of ritual expressions is also found in other Rai ritual languages (Gaenszle 2002:161-69; Gaenszle et al. 2005:41-45).

Our dictionary of Puma (Rai et al. 2009) contains a total of 393 ritual noun expressions, of which 231 can be classified as (irreversible) binomials. These usually consist of two trisyllabic or (sometimes) disyllabic limbs, in which all of the limbs contain the same number of syllables, as well as identical final syllables. However, there are also limbs with four syllables, and a number of exceptional cases in which the two limbs have different numbers of syllables. Some examples of typical binomials are given in table 1.

\section{Table 1. Examples of Typical Binomials}

\begin{tabular}{|c|c|c|}
\hline BINOMIAL & PART OF SPEECH & MEANING \\
\hline apturoy tuwaroy & n. & 'spirit of shaman; hunter spirit; stinging pain' \\
\hline bettumbuy moribuy & $\mathrm{n}$. & 'flower sp.' \\
\hline chorom borom & n. & 'dried meat’ \\
\hline chımahun rımahun & $\mathrm{n}$. & 'peace and prosperity; general well-being' \\
\hline
\end{tabular}

In many binomials the semantic weight lies on the last syllable, as in the

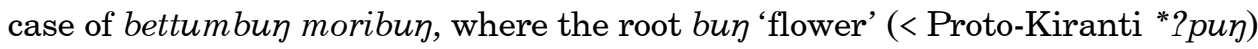
is the general meaning and the preceding syllables serve to qualify it. In this way, many binomials can be analyzed in terms of semantic content. For example, chımahun rımahun contains the noun hun 'plenty' preceded by chıma 'prosperity' and the adjective 'pure', thus meaning literally 'plenty of prosperity and purity' or, in short, 'peace and prosperity' or 'general well-being'. Some binomials are constructed from verbal roots, as in the first example in table 1; apturon tuwaron contains the verbs apma 'to shoot' and tukma 'to hurt', while roy is said to derive from rayma 'to burn'.

The morphology and etymology of binomials are highly varied and often problematic. A systematic analysis of this variation would go beyond the scope of this article; instead, an illustration of some irregular constructions in table 2 will suffice. ${ }^{11}$ 
Table 2. Examples of Irregular Binomial Constructions

\begin{tabular}{|c|c|c|}
\hline BINOMIAL & ART OF SPEECH & MEANING \\
\hline buktukhu sakojkha & n. & $\begin{array}{l}\text { 'womb' (buk n. 'stomach', tukma v.i. 'to ache'; } \\
\text { sakonkha puonkha is another ritual expression } \\
\text { referring to the mythical place of origin of all } \\
\text { living beings; -kha is the locative nominalizer) }\end{array}$ \\
\hline nanwara bekcuri & n. & $\begin{array}{l}\text { 'dizzyness' (both limbs allude to other ritual } \\
\text { binomials: naywara huwara means 'headache' } \\
\text { and bekcuri bichu or benchuri bichu refer to a } \\
\text { 'wound by cutting'; cf. ben 'iron weapon') }\end{array}$ \\
\hline nawa capha & n. & $\begin{array}{l}\text { 'boat' (nawa is related to Nepali nāu 'boat'; } \\
\text { capha 'boat' is only found in ritual speech) }\end{array}$ \\
\hline khılihoэра mılihoэma & n. & $\begin{array}{l}\text { 'male and female ancestors' (hoypa 'king', } \\
\text { honma 'queen' < *han 'chief'; both limbs have } \\
\text { four syllables, with repetition in syllables two } \\
\text { and three rather than the last syllable) }\end{array}$ \\
\hline
\end{tabular}

Puma also has some ritual-language verbs-thirty-four altogether, of which, interestingly, eight are binomials. Such binomial verbs have so far not been reported to exist in other Rai ritual languages. ${ }^{12}$ Some examples are shown in table 3 .

Table 3. Binomial Ritual-Language Verbs

\begin{tabular}{lll}
\hline BINOMIAL & PART OF SPEECH & MEANING \\
cakma banma & v.t. & 'talk' \\
kapma cenma & v. & 'ask for protection' \\
laphapma kuphapma & v.i. & 'get trouble; experience disaster; feel barrier' \\
\hline
\end{tabular}

Moreover, there are a few ritual-language adverbs (ten) and adjectives (six), of which some are binomials (four and one, respectively); examples are shown in table 4 .

\section{Table 4. Binomial Ritual-Language Adverbs and Adjectives}

\begin{tabular}{lcl}
\hline BINOMIAL & PART OF SPEECH & MEANING \\
aseyu busuyu & adv. & 'before; very beginning; long time ago' \\
deysa busa & adv. & 'forward; opposite; reverse' \\
cokho nito & adj. & 'pure; clean' (< N cokho 'ritually pure', N nīti \\
& & 'conduct') \\
\hline
\end{tabular}

It should also be added that some pronouns (two) and a number of grammatical markers (twenty) are distinct in the ritual language, but these are not binomials. Some examples of ritual-language grammatical markers are shown in table $5 .{ }^{13}$ 
Table 5. Ritual-Language Grammatical Markers

GRAMMATICAL MARKER

$$
\begin{aligned}
& \text {-heda } \\
& \text {-onei } \\
& \text {-sa }
\end{aligned}
$$

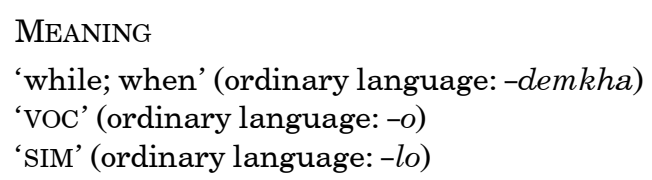

However, the nonnominal cases are clearly the exception and the vast majority of binomials are nouns. Often these binomial nouns are used in enumerations, which gives additional emphasis to the nouns. The enumeration in (3) is an example of the first-fruits offering, in which protection from various dangers is requested.

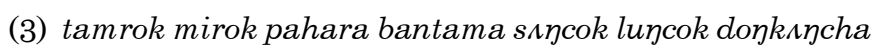

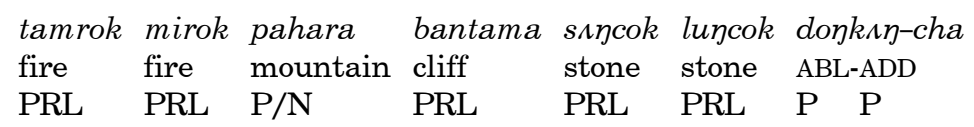

'from bush fire, mountain cliffs, and stones' (nuwagi_01.100)

This "nouniness," the predominant usage of nominal phrases, we argue, is a central attribute of Rai ritual speech. The binomials give a special emphasis, or "thickness," to ritual names and objects, thus contributing to the construction of a distinct ritual ontology. The full meaning of this use of binomials, however, only emerges when one compares it with the usage patterns of nouns in ordinary speech.

4. Noun-to-verb ratios. Like many other languages in the world, Kiranti languages are characterized by a relatively low usage of nominal expressions, keeping reference to people and things at a minimum (Bickel 2003; Stoll et al. 2011). In everyday conversations and narratives, reference is typically left vague as long and as much as possible and explicit mentioning of referents usually occurs only when the message would become completely incomprehensible without it (Stoll and Bickel 2009). On the other hand, speech is characterized by a preponderance of verbal expressions, resulting in vivid description of temporal patterns and close attention to details of events. This characteristic of everyday language is in stark contrast to what we have noted above in ritual language, suggesting that there is a systematic difference in the noun-to-verb ratio between the two speech styles.

4.1. Coding and methods. To test this hypothesis, we performed a quantitative analysis of the part of our corpus that is fully tagged for parts of speech and contains sufficient metadata on speakers, recording context, genre, etc. This includes a total of about seventy thousand words, divided over 179 sessions (stretches of discourse that were videotaped without interruption). We calculated the noun-to-verb ratio as the frequencies of noun tokens divided by 
the frequency of noun and verb tokens summed together (so as to avoid division by zero in case a speaker uses no verbs at all).

One obvious way to calculate the proportions of nouns in this sense is by individual speaker within a session; this would control for variation in context and individual habits. However, the contributions of speakers (a total of 143 in the corpus) follows a power-law distribution, with the large majority of them contributing only a very few utterances. The problem that results from this is that if a speaker contributes only a small number of utterances, the proportion of nouns cannot be reliably estimated. First, there is a discreteness problem. With only a handful of words, the proportion of nouns does not vary continuously between 0 and 1, but rather varies in discrete jumps: for example, if there are three words in the sample, there are four discrete values for the proportion of nouns, $0,1 / 3,2 / 3$, and 1 . Moreover, in the worst case (which occurs fifty-nine times in our corpus), the speaker contributes just one noun or one verb within a session, and this leads to a distorted estimate of the probability of using nouns or verbs in the overall corpus. In response to these problems, we calculated figures by session, counting together the utterances of all speakers in a given session on the assumption that contextual factors that may affect the proportion of nouns remain sufficiently constant during a single session. ${ }^{14}$

4.2. Results. Figure 1 shows the proportions of nouns per session for everyday speech as opposed to rituals. The difference between means $(\mu=0.62$ vs. $\mu=$ 0.68 ) is statistically significant $(t=-2.29, d f=60.37, p=0.026, N=151)$.

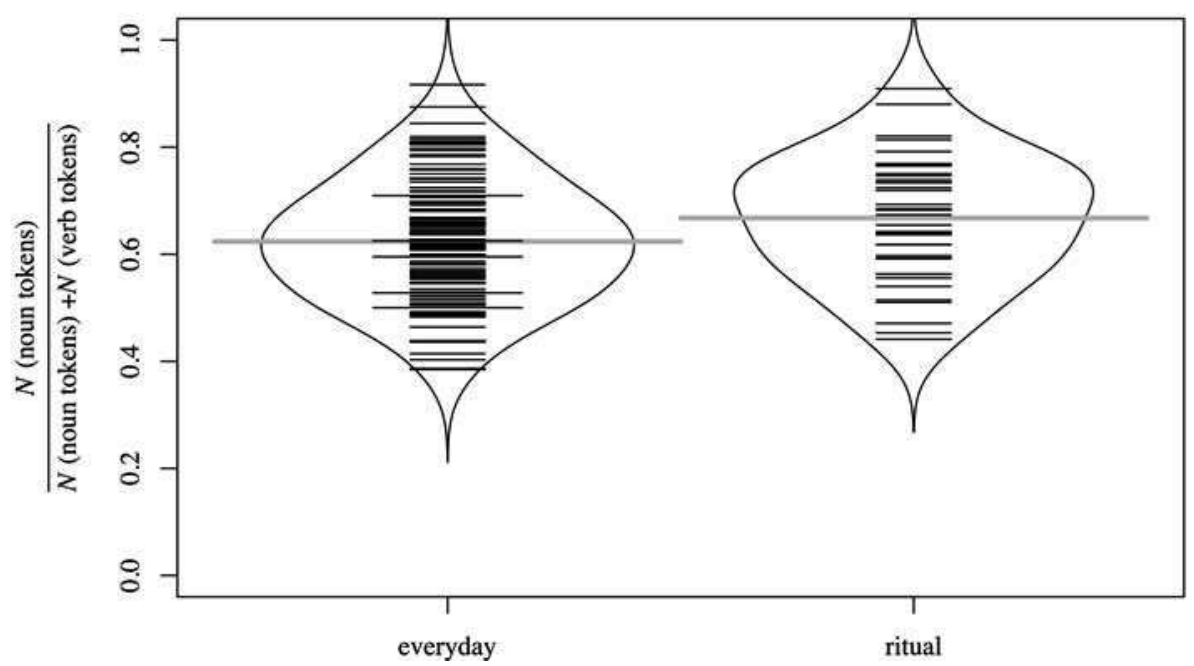

Figure 1. Probability density estimates of proportions of noun tokens per session: ritual vs. everyday language. (The polygons describe symmetrically mirrored density estimates; the short black horizontal lines represent the proportions of noun tokens in individual sessions; and the long grey horizontal lines represent the genre averages.) 
We also analyzed whether there is a difference between the two styles of

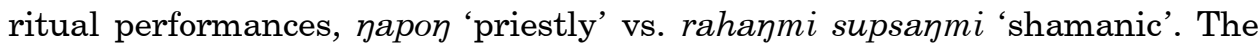
discussion in section 3 suggests that the shamanic style is characterized by an increased mastery of binomials, which leads us to expect a higher proportion of nouns in this style. Figure 2 shows the results. The difference in means $(\mu=0.67$ vs. $\mu=0.75$ ) is borderline significant $(t=-1.81, d f=11.95, p=0.095$; permutation test $p=0.083$ ). This suggests that there is a possible trend; the lack of more pronounced statistical significance is plausibly due to the relatively small sample size (twenty sessions).

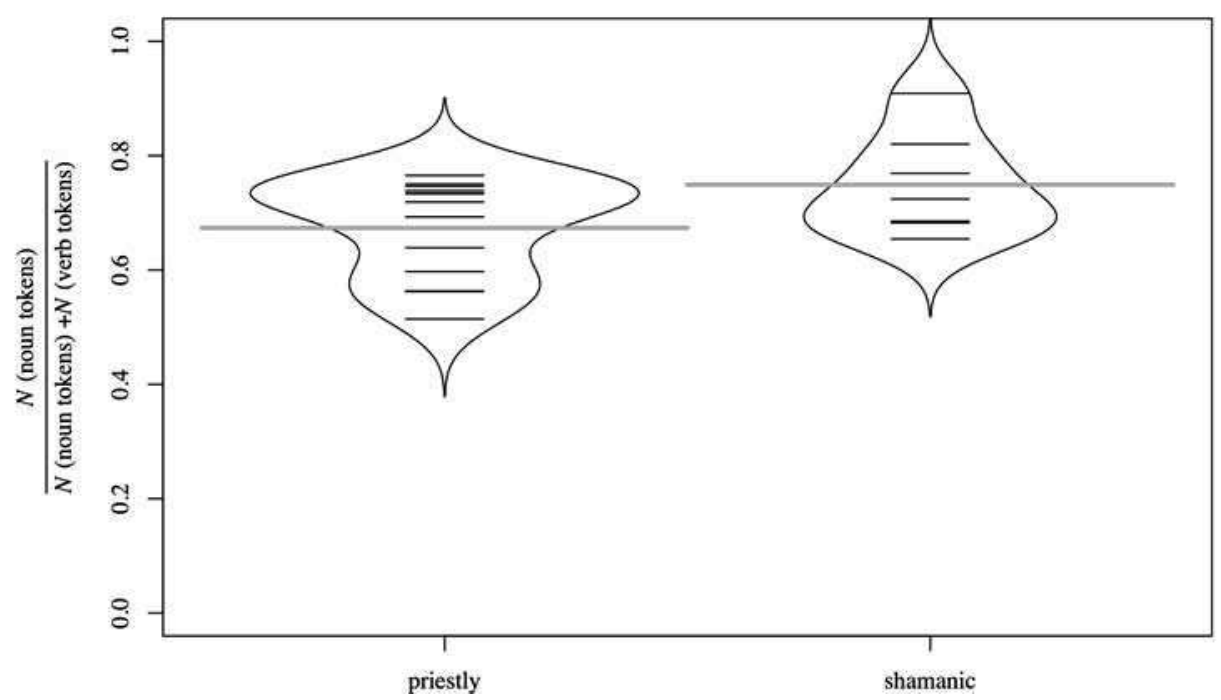

Figure 2. Probability density estimates of proportions of noun tokens per session: shamanic vs. priestly incantations (same plotting conventions as in figure 1).

5. Discussion. The results clearly indicate that ritual speech is characterized by a significant increase in the use of nouns in comparison to everyday speech. In other words, it is more "nouny." Similar results are obtained by calculating the noun-to-verb ratio in terms of types instead of tokens. However, we have excluded the latter calculations in this article because they would obscure the high frequency of repetitions in ritual speech, which is, in fact, an important aspect of its character.

Considering the heavy use of binomials formed from nouns discussed above, this result is, of course, not surprising. However, what we want to stress is that the effect of this linguistic practice is not simply the marking of a difference, i.e., the marking of a "sacred" form of speech as distinct from a "profane" form. Though this is certainly one important part of the effect of binomials, there is more to it. Since everyday speech is characterized by a relatively low noun-toverb ratio, the heavy use of nouns is particularly striking and appears like an inversion (or mirror image) of the ordinary way of speaking. The increase of 
nouniness implies a reduction of verbiness, and this is a feature that characterizes ritual discourse as a whole.

The second finding, the observation that the shamanic genres tend to have a higher proportion of nouns than priestly genres, may at first seem surprising. To be sure, shamans have a higher linguistic competence, as they know a larger variety of ritual texts and have to memorize fairly lengthy recitations. Thus, they have a more comprehensive knowledge of ritual terms. But this does not necessarily imply a higher density of noun usage. However, if we accept that it is not only the use of ritual nouns as such, but the degree of nouniness, that marks ritual discourse in distinction to ordinary speech, then one can say that shamans tend to use a slightly more "ritualized" form of speaking. The effect of this is the production of a register of speech that is perceived as more powerful or sacred (and hence more awe-inspiring).

Similar observations that differentiate ritual speech genres along a continuum have been made elsewhere. Kuipers's study (1990) of Weyewa ritual speech brings out a "continuum of style" ranging from relatively dialogic genres to relatively monologic ones, the former being marked by a high degree of contextualization (including deictics, discourse markers, etc.), and the latter being marked by a high degree of (en)textualization (including frequent use of "couplet names,” etc.). Likewise (and partly taking up Kuipers's approach), Gaenszle (2002:85-111) analyzes Mewahang speech genres and ritual speech competence along a continuum ranging from relatively informal ways of speaking (specifically, ceremonial dialogues) to relatively formal expert genres (specifically, ancestral offerings involving ritual journeys). The analysis presented here basically confirms the applicability of these findings concerning a continuum of style in the case of the Puma Rai. Of course, we have focused only on the nounto-verb ratio, and further discursive analysis of what constitutes style and genre remains to be done. But the approach taken here shows that the statistical analysis of speech corpora can contribute significantly to such an enterprise.

Let us return to the question of noun usage in shamanic speech. What are the overt reasons for a higher proportion of nouns? The situation can be explained by the occurrence of verbal ritual journeys, with lengthy enumerations of place names, the naming of objects, spiritual beings and afflictions, and the knowledge of a wide array of ancestral entities in general. Shamans are known for their proclivity to recite long lists and chant enumerations. These rhetorical techniques are part of their socially expected ritual competences. They can be seen as contributing to the construction of the ancestral cosmos of the mundhum. The Puma shaman, as the most competent expert in ritual speech, embodies this ancestral knowledge more than anyone else.

6. Conclusions. We have discussed the various kinds of explanations offered in earlier work on the phenomenon of binomials. Explanations in terms of poetics are largely inspired by structuralist ideas and argue that binomials have 
to be seen as part of a more pervasive parallelism. However, it remains unclear why all ritual languages marked by parallelism do not have binomials. The sociological approach regards binomials as a means for the construction of social hierarchies and linguistic authority, but has little to say about the way binomials are structured or produced. Moreover, culturalist approaches, which see binomials as linked to the system of (dual) symbolic classification, have had to acknowledge that only a part of the existing forms can be analyzed in this way. All these explanations have their validity, and we do not mean to reject them. Rather, by focusing on the noun-to-verb ratio, we want to add a further perspective and point out the effect of binomials on discourse as a whole, or what can be called discursive style.

The question can be posed more specifically: What is the effect of a pronounced nouniness on discursive style? Philologists, linguists, anthropologists, and literary scholars have given various answers, which can only be sketched here in order to indicate the direction of possible further inquiries.

The predominant use of nouns was long ago termed "Nominalstil" by the Sanskritist and Indologist Hermann Jacobi (1903), who showed that it is characteristic of a particular formal and abstract style of writing-specifically, Sanskrit scientific language. As Jacobi argues, the "nominal style" developed when a number of syntactic processes of nominalization came into greater use in the course of increasing intellectualization of both scientific and literary discourse.

More recently, linguistic anthropologists have pointed out that a nominal style correlates with a higher degree of formality (e.g., in legal language) and social distance (e.g., in contexts of politeness). In the case of Puma, it is also true that the heavy use of nouns increases the formality and general politeness of a speech genre. Above all, it enhances the concreteness of particular entities and stresses their quality as objects.

In literary theory the notion of textual or discursive density has been used to distinguish literary texts according to their treatment of the text-to-world relationship. In his book Fictional Worlds, Thomas Pavel (1986) argues that essentially all literary texts construct fictional worlds through linguistic means and thereby give different elaborations and emphases to this relationship.

To render less vague the impression that a text efficiently leads to its set of worlds, we could speak of a relative density, in whose assessment we may include the relation between texts and worlds, and such variables as the external information needed to understand the text, its narrative crowding, the ratio between action and description, and the epistemic paths chosen by a text. [1986:102; emphasis in original]

Various textual and stylistic strategies are implied here, but what is crucial is that they all contribute to a greater or lesser fluidity of a text for the reader or hearer. A text full of nouns makes it dense and more difficult to read.

All these approaches can contribute to an understanding of the use of ritual nouns. Of course, ritual speech is not academic, nor intellectual, nor simply 
fictional. It is abstract and objectifying in the sense that it refers not so much to descriptive and empirical, but rather to ideal (or cognitive) entities. Ritual nouns are crucial for the construction of a "thick" or dense ritual world; they constitute a ritual ontology. In the cases discussed here, this ontology gives more weight to ritual objects and entities; in other words, it induces a focus on ritual "things" that exist on a different plane of reality. At the same time, such usage creates a social situation marked by respect, reverence, and dignity. It is polite and formal speech expressing the distinctness of sacred beings.

This is not the place to describe further details of the characteristics of ritual speech. All we want to stress is that the shift from ordinary speech to ritual speech in Puma involves not only a shift in discursive style, but also a shift in discursive density, or, more generally, in linguistic ontology. Of course, this cannot be generalized, as other ritual languages may employ different strategies. Nonetheless, as we have seen in our example, the use of binomials, even if these include paired verbs, can effect a significant change in speech practice: by giving emphasis to distinctive names and ritual entities rather than action, it contributes to the creation of a different, somehow richer and denser discursive world constructed in performance.

\section{Notes}

Acknowledgments. This study is based on the Puma corpus developed by the Chintang and Puma Documentation Project (CPDP), which was supported by the Volkswagen Foundation, DoBeS grant nos. BI 799/1-2 and II/81 961, in the years 2004-8. Author contributions are as follows: Gaenszle carried out the main analysis; Bickel contributed the quantative analysis; Gaenszle and Bickel wrote the article; and all of the authors contributed to data collection and analysis. We are grateful to the anonymous reviewers for their helpful comments.

Abbreviations. The following grammatical abbreviations are used (in accordance with the Leipzig Glossing Rules: www.eva.mpg.de/lingua/resources/glossing-rules. php): 3 = third person; $\mathrm{ABL}=$ ablative; $\mathrm{ADD}=$ additive focus ('also, even'); $\mathrm{EMPH}=$ emphatic; GEN = genitive; $\mathrm{IMP}=$ imperative; $\mathrm{POSS}=$ possessive; $\mathrm{SG}=$ singular; $\mathrm{SIM}=$ simultaneous; $\mathrm{VOC}=$ vocative.

We also indicate the linguistic provenance of each morpheme: $\mathrm{N}=$ Nepali; $\mathrm{P}=\mathrm{Puma}$ $\mathrm{PRL}=$ Puma ritual language.

1. We use the term binomial in the sense of "pairs of semantically related terms of the same grammatical category," as, for example, in a binomial nomenclature, not in the sense of its mathematical use. We are aware of potential ambiguities, but we decided to stick to the term as it has become well established in the context of Kiranti studies.

2. The Puma Rai are one of more than two dozen subgroups of the ethnic group known as "Rai", which, along with some other groups, in particular the Limbu, belong to the Kiranti. The Rai subgroups have distinct languages—not simply dialects-as well as distinct cultures and identities. Therefore, the term "Rai" is often dropped and one can simply speak of the Puma.

3. Although the Puma language is still widely spoken in the five villages of the original settlement area in Khotang District (we estimate by five thousand of the roughly six thousand residents), members of the younger generations increasingly prefer to 
speak Nepali, the national language. As Puma does not have a written language, the rich oral tradition known as mundhum is also endangered.

4. The terms "everyday," "ordinary," and "colloquial" language are all used interchangeably to denote a nonritual speech register. Generally, ritual and nonritual registers are clearly distinguished, but the degrees of formality may vary in different genres, so it is best to see them at opposite ends of a continuum (Gaenszle 2002:110-11; Kuipers 1990:55-60).

5. This is the kind of pairing that had already been described by Robert Lowth in 1778 as "parallel terms" (quoted in Jakobson 1966:399), as indicated above.

6. Several publications by N. J. Allen, have pointed in this direction-in particular, (1972) on the up-down dichotomy, (1978) on binomials among the Thulung Rai, and, in a more general context (2000:39-60).

7. Allen does not provide a gloss for $c i$, but in the Thulung language this is clearly a dual particle.

8. We are using Allen's term "limb" (1978:250-52) for the components of a binomial because it is convenient and has gained wide currency in studies on Himalayan ritual languages.

9. The name Budhahay is derived from the Nepali term burho 'old' and Kiranti *han 'king, chief'. In spite of this hybrid name, this Old King is a typical ancestral figure in the local Rai mythologies, who is described as a powerful ruler known to have once fought the invading Shah armies (Gaenszle et al. 2005). The shamanic séance itself is entirely Kiranti in style, showing little Hindu or Nepali influence. Likewise, the Guru Pujā, in spite of the name being Nepali, is a thoroughly Kiranti ritual that uses very few Nepali words. In fact, it is the most elaborate shamanic performance, addressed to the mythical creator couple Sumnima and Paruhang. It also includes the typical Rai dances, the socalled sili. The Guru Pujā is also referred to as Thapsan, which means 'ceremony'. It may be surprising that such important rituals are known by Nepali names, but in a multiethnic context where Nepali is the lingua franca, it is quite common to find that names (in particular, personal names) have been put into Nepali form.

10. The corpus is accessible at the DoBeS archive (http://corpus1.mpi.nl/ds/imdi_ browser).

11. In our corpus we found only six ritual binomials that contain Nepali elements. Four of these are expressions with two Nepali limbs, e.g., chora bayu 'spirits of the dead' (from chaũro 'spirit of a witch', bāyu 'spirit of the dead'; similar terms are found in Mewahang ritual speech [Gaenszle 2002:231-32, 258-59]). The other two are hybrids, like nawa capha, the third item in table 2. Interestingly, in each case the Nepali limb comes first.

12. As one reviewer points out, in other Tibeto-Burman languages (such as Lisu and Lahu) pairings occur in various form classes.

13. It would be worth pursuing the question of how grammatical markers in ordinary and ritual language relate to Tibeto-Burman cognates, but such etymological research would be beyond the scope of this article.

14. All computations were done in $R$ ( $R$ Development Core Team 2009), with the additional package beanplot (Kampstra 2008) for visualization.

\section{References}

Allen, Nicholas J.

1972 The Vertical Dimension in Thulung Classification. Journal of the Anthropological Society of Oxford 3:81-94.

1978 Sewala Puja Bintila Puja: Notes on Thulung Ritual Language. Kailash 6(4): $237-56$. 
2000 Categories and Classifications: Maussian Reflections on the Social. New York: Berghahn Books.

Bickel, Balthasar

2003 Referential Density in Discourse and Syntactic Typology. Language 79: 708-36.

Blackburn, Stuart

2010 The Sun Rises: A Shaman's Chant, Ritual Exchange, and Fertility in the Apatani Valley. Leiden: Brill.

Fox, James J.

1975 On Binary Categories and Primary Symbols. In The Interpretation of Symbolism, edited by Roy G. Willis, 99-132. London: Malaby Press.

1977 Roman Jakobson and the Comparative Study of Parallelism. In Roman Jakobson: Echoes of His Scholarship, edited by Daniel Armstrong and C. H. van Schooneveld, 59-90. Lisse: Peter de Ridder Press.

1988 Introduction. In To Speak in Pairs: Essays on the Ritual Languages of Eastern Indonesia, edited by James J. Fox, 1-28. Cambridge: Cambridge

Gaenszle, Martin University Press.

2002 Ancestral Voices: Oral Ritual Texts and Their Social Contexts among the Mewahang Rai in East Nepal. Münster: Lit.

Gaenszle, Martin, Balthasar Bickel, Goma Banjade, Elena Lieven, Netra Paudyal, Ichchha Rai, Manoj Rai, Novel Kishor Rai, and Sabine Stoll

2005 Worshiping the King God: A Preliminary Analysis of Chintang Ritual Language in the Invocation of Rajdeo. In Contemporary Issues in Nepalese Linguistics, edited by Yogendra P. Yadava, 33-47. Kathmandu: Linguistic Society of Nepal.

Höfer, András

1994 A Recitation of the Tamang Shaman in Nepal. Bonn: VGH Wissenschaftsverlag.

Jacobi, Hermann

1903 Über den nominalen Stil des wissenschaftlichen Sanskrit. Indogermanische Forschungen 14:236-51.

Jakobson, Roman

1960 Closing Statement: Linguistics and Poetics. In Style in Language, edited by Thomas A. Sebeok, 350-77. Cambridge, Mass.: MIT Press.

1966 Grammatical Parallelism and Its Russian Facet. Language 42(2):399-429.

Kampstra, P.

2008 Beanplot: A Boxplot Alternative for Visual Comparison of Distributions.

Kuipers, Joel Journal of Statistical Software, Code Snippets 28:1-9.

1990 Power in Performance: The Creation of Textual Authority in Weyewa Malkiel, Yakov Ritual Speech. Philadelphia: University of Pennsylvania Press.

1959 Studies in Irreversible Binomials. Lingua 8:113-60.

Pavel, Thomas G.

1986 Fictional Worlds. Cambridge, Mass.: Harvard University Press.

$\mathrm{R}$ Development Core Team

2009 R: A Language and Environment for Statistical Computing. Vienna: R Foundation for Statistical Computing (http://www.r-project.org).

Rai, Ichchha P.

2007 An Outline of the Chintang Mundum/Ritual Language. M.A. thesis, Tribhuvan University, Kathmandu. 
Rai, Vishnu S., Shree K. Rai, Narayan P. Gautam (Sharma), Arjun Rai, Martin Gaenszle, and Balthasar Bickel

2009 Puma dictionary: Puma-Nepali-English. DOBES Archive (http://www. mpi.nl/DOBES).

Rai, Ichchha P., Balthasar Bickel, Elena Lieven, Goma Banjade, Martin Gaenszle, Manoj

Rai, Netra P. Paudyal, Novel K. Rai, Sabine Stoll, and Toya N. Bhatta

2009 Mundum: A Case Study of Chintang Ritual Language. In Locality, History, Memory: The Making of the Citizen in South Asia, edited by Rila Mukherjee and M. N. Rajesh, 20-33. Newcastle upon Tyne: Cambridge Scholars.

Stoll, Sabine, and Balthasar Bickel

2009 How Deep Are Differences in Referential Density? In Crosslinguistic Approaches to the Psychology of Language: Research in the Tradition of Dan Isaac Slobin, edited by Jiansheng Guo, Elena Lieven, Nancy Budwig, Susan Ervin-Tripp, Keiko Nakamura, and Şeyda Özçalişkan, 543-55. New York: Psychology Press.

Stoll, Sabine, Balthasar Bickel, Elena Lieven, Goma Banjade, Toya N. Bhatta, Martin Gaenszle, Netra P. Paudyal, Judith Pettigrew, Ichchha P. Rai, Manoj Rai, and Novel K. Rai

2011 Nouns and Verbs in Chintang: Children's Usage and Surrounding Adult Speech. Journal of Child Language. (Available on CJO 2011 doi:10.1017/ S0305000911000080).

Strickland, Simon S.

1987 Notes on the Language of the Gurung Pe. Journal of the Royal Asiatic Society 1:53-76.

Vorberg, Annegrit, Balthasar Bickel, Martin Gaenszle, Gereon Müller, Manoj Rai, Goma Banjade, Netra P. Paudyal, Toya N. Bhatta, and Ichchha P. Rai

2009 An Optimality-Theoretic Analysis of Binomials in Chintang Ritual Language. MS. (http://www.spw.uzh.ch/clrp/papers/bibom.pdf). 